Anuario de Estudios Medievales (AEM)

36/1, enero-junio de 2006

pp. 171-199

ISSN 0066-5061

\title{
ORDEN, CONSERVACIÓN Y OSTENTACIÓN: EL CARTULARIO DE LA CATEDRAL DE SIGÜENZA \\ (C. 1212)
}

$†$ CARLOS SÁEZ

Universidad de Alcalà

Resumen: Los cartularios son libros en los que se copiaban documentos recibidos por algunas instituciones. Parece que aparecen en España a finales del siglo XI y se usan hasta el siglo XIX. Este trabajo estudia el cartulario de la catedral de Sigüenza, datado a principios del siglo XIII. En él se tratan sus características codicológicas, su estructura y su razón de ser.

Palabras clave: Cartularios; Diplomática; Codicología; Sigüenza.
Abstract: Cartories are books in which written records recieved by institutions were copied. They seem to appear in Spain in the late XIth century and they were used until the XIXth. This paper studies the cartory from the catedral of Sigüenza, dated in the early XIIIth century. It deals with his codicological caracteristics, with his structure and with his reason of being.

Keywords: Cartories; Diplomatics; Codicology; Sigüenza.

1. Introducción.- 2. Prospección codicológica.- 3. La razón de ser del cartulario: 1. Utilidad. 2. Guarda de los derechos. 3. La conservación de la memoria. 4. Ostentación. 5. El obispo don Rodrigo.- 6. Ilustraciones. 


\section{INTRODUCCIÓN ${ }^{1}$}

A pesar de la riqueza de su fondo de manuscritos medievales, que se remontan hasta el siglo X, la biblioteca capitular de Sigüenza no goza de la fama de otras españolas, como Toledo, Sevilla o Santiago de Compostela, que están en la mente de todos. El escaso desarrollo que, si se compara con estas ciudades, ha sufrido Sigüenza desde los siglos medievales, ha motivado su aislamiento, en parte debido a su situación alejada de las principales vías de comunicación. Hoy es un pequeño lugar que progresa gracias a la agricultura y al turismo. En la Edad Media la plaza seguntina fue conquistada de manos musulmanas en la segunda década del siglo XII por su primer obispo, el aquitano Bernardo de Agen (1121-1152) ${ }^{2}$, lo que propició que en sus primeros años estuviera bajo la órbita aragonesa. Más adelante caería bajo influencia castellana para, como otros muchos lugares del centro peninsular, comenzar un largo decaer conforme la frontera con la España musulmana se iba alejando hacia el sur. Aún así, Sigüenza tuvo siempre una vida cultural de alto nivel que culminó con la fundación de una universidad en el siglo XV, que pervivió hasta su supresión en las desamortizaciones del siglo XIX ${ }^{3}$.

Sin embargo, lo que aquí interesa es abordar el estudio de la biblioteca medieval de la catedral seguntina y en concreto del más antiguo de sus códices diplomáticos, el cartulario del siglo XIII. La personalidad y el alto nivel cultural de los primeros prelados seguntinos, de origen francés, fueron las bases sobre las que se asentó su rica biblioteca, cuyo núcleo original está formado por un fondillo de libros traídos desde su Aquitania originaria por el primer obispo de la diócesis, Bernardo de Agen. Ello justifica que hallemos en la catedral códices escritos en carolina, letra que ya no se utilizaba cuando los ejércitos cristianos recuperaron la plaza de manos musulmanas. El número de tales libros es muy corto y no debe pasar de una decena, a tenor de los dos primeros inventarios que conocemos, que ya corresponden al siglo XIII y que

\footnotetext{
${ }^{1}$ Este trabajo se enmarca dentro del proyecto BHA 2002-02541 titulado Usos, prácticas y modelos de conservación de lo escrito en la península ibérica entre los siglos XI al XVII, subvencionado por el Ministerio de Ciencia y Tecnología y dirigido por Carlos Sáez (Universidad de Alcalá).

${ }^{2}$ Sobre estos primeros años pueden verse: Adrián BLÁZQUEZ GARBAJOSA, La reconquista de Sigüenza y su significación geopolítica regional, «Wad-al-Hayyara», 12 (1985), pp. 3542; y la voz Sigüenza-Guadalajara, Diócesis de, en el Diccionario de Historia Eclesiástica de España, Madrid, 1975, IV, pp. 2467-2476.

${ }^{3}$ Una panorámica de su existencia se esboza en Francisco Javier DÁvARA, Síntesis Histórica de la Universidad de Sigüenza, «Anales Seguntinos», 6 (1990), pp. 23-35.
} 
no superan en ningún caso los veinte ejemplares. Pero en poco tiempo la biblioteca ganó en riqueza y en el siglo XIV se confeccionaron dos listas más completas, la más extensa de las cuales llega a los 280 libros $^{4}$. Hoy los manuscritos medievales del archivo catedralicio son más de cien y se encuentran a falta de un inventario completo y actualizado. Como es natural, la biblioteca medieval ha sufrido muchas pérdidas en diversos momentos ${ }^{5}$. Son testigos de su riqueza pasada un códice que conserva restos de tinta procedentes de una guarda escrita en escritura uncial ${ }^{6}$ o las noticias de la existencia de algún manuscrito en visigótica entre sus fondos. ${ }^{7}$ En el inventario de 1339 figura la siguiente noticia, que suele ser indicativa de escritura visigótica en textos españoles: Item otro libro de mala letra que no se puede leer ${ }^{8}$.

Pero el objeto de este trabajo, como se ha dicho, es el estudio de uno de los libros emblemáticos de la catedral, su cartulario más antiguo. Este precioso libro contiene una mina de informaciones sobre Sigüenza y su entorno y, como suele suceder, no había sido estudiado en su conjunto, aun-

${ }^{4}$ Todos los inventarios medievales fueron editados por J. Rius Serra, Inventario de los manuscritos de la catedral de Sigüenza, con apéndice de A. DE FEDERICO FERNÁNDEZ, «Hispania Sacra», 3 (1950), pp. 432 y ss. El inventario más antiguo cita los siguientes libros, entre los que se encontrarían los aportados por Bernardo de Agen: Decretales; Historias magistri $P$. manducatoris; Vitas patrum; Quartum librum sententiarum; Dialogus Gregorii; Cintillarum; Regulam beati Augustini; Missale et evangelia; Epistolas; Psalterium; Capitularium; Duo ordinaria, videlicet maius et minus; Liber miraculorum beate Marie; Zmaragdum; Omelias (RIUS SERRA, p. 432). Sin embargo la edición de estos inventarios debe ser revisada pues, a pesar de la fecha de su publicación, fue confeccionada en 1926, es decir antes de la Guerra Civil española, en la que la catedral seguntina sufrió mucho. Su archivo y biblioteca fueron alcanzados por varias bombas, sus techos se desplomaron y sepultaron libros y documentos junto a cadáveres de combatientes. La reconstrucción de la biblioteca fue muy laboriosa y duró años. La inició y la describe Hilario YÁBEN en su Catálogo del Archivo catedralicio de Sigüenza con algunos documentos inéditos, Pamplona, 1937.

${ }^{5}$ BEER, en Handschriftenschätze Spaniens, Viena, 1894 y Amsterdam, 1970, pp. 403-404 menciona la existencia en el siglo XIX de un inventario de los manuscritos de la catedral, confeccionado por Vicente de Lafuente, que tenía no menos de 200 títulos.

${ }^{6}$ Códice con la signatura $81 \mathrm{Mod}$.

${ }^{7}$ Todavía se encuentra en el Archivo Histórico Diocesano de Sigüenza una hoja en visigótica de un códice conciliar procedente del monasterio de Celanova, en Galicia, descrito ya por Ambrosio de Morales. Fue catalogada por Agustín MILLARES CARLO en Contribución al corpus de códices visigóticos, Madrid, 1931, pp. 237-240. Curiosamente este fragmento no se incluye en la obra póstuma de Millares recientemente editada: Corpus de códices visigóticos, Centro Asociado de la UNED, Las Palmas de Gran Canaria, 1999. Si da noticia esta obra de otra hoja visigótica, y además bilingüe latín-árabe, que la catedral de Sigüenza donó al Vaticano en el siglo XIX. Hoy se desconoce su signatura.

${ }^{8}$ RIUS SERRA, cit., p. 441 . 
que parte de su documentación ha sido citada y editada repetidas veces ${ }^{9}$. El libro reproduce un momento preciso de la vida del archivo catedralicio, que podríamos situar en el primer tercio del siglo XIII, como más adelante intentaremos demostrar. Asimismo, nos suministra información sobre la organización del archivo en su primer siglo de existencia. Reconquistada la ciudad en el año 1124, bastó una escasa centuria para que los diplomas de obispo y canónigos reclamaran la confección de un códice diplomático. Los casi 150 documentos que éste contiene reproducen con fidelidad la forma en que estaba estructurado el archivo de la catedral en el momento de su confección y, por lo tanto, su estudio es imprescindible para conocer la historia misma de sede y ciudad seguntinas en los siglos XII y XIII. El cartulario no contiene todos los diplomas que existían en aquel tiempo en el archivo, pero sin duda recoge los que, por las razones que veremos, tenían más importancia ante los ojos de quien dispuso su confección.

La primera noticia que conservamos del cartulario procede de un inventario de libros confeccionado a principios del siglo XIV, en el que se le denomina Liber privilegiorum $^{10}$. Más tarde, otro inventario de 1339 menciona: Item dos libros en que están todos los privillejos de la eglesia de Sigüença, que comiença: Regie maiestatis (lámina $1, \mathrm{f} 7 \mathrm{r})^{11}$. Se trata sin duda de una alusión al cartulario, que en este momento estaba dividido en dos volúmenes diferentes, el primero de los cuales llegaba hasta el folio 66 y abarcaba la documentación real. El segundo comenzaba en la documentación pontificia y abarcaba hasta el fin del manuscrito actual. El inventario lo incluye entre los libros que están en los armarios del sagrario y menciona de forma explícita que se hallaba encuadernado con tablas ${ }^{12}$. Definitivamente encuadernado en el siglo XVI, el códice se ha mantenido en perfecto estado hasta nuestros días. Su signatura actual es $14 \mathrm{Mod}$.

${ }^{9}$ Muchos documentos fueron editados por Toribio Minguella y ARNEDO, Historia de la diócesis de Sigüenza y de sus obispos, 3 vols., Madrid, 1910-1913.

${ }^{10}$ RIUS SERRA, cit., p. 435.

${ }^{11}$ Así comienza precisamente el primer documento del cartulario, fechado en 1129, una donación de Alfonso VII a la catedral (lámina 1, f7r, línea 3).

${ }^{12}$ RiUs SERRA, cit., p. 439. 


\section{PROSPECCIÓN CODICOLÓGICA}

El libro está encuadernado en tabla forrada de cuero de color marrón claro tirando a rojizo, repujado con motivos platerescos propios del siglo XVI. La encuadernación está muy bien conservada aunque algo desgastada por el uso. Mide 33 x $23 \mathrm{~cm}$., y $5 \mathrm{~cm}$. de lomo aproximadamente. El manuscrito fue guillotinado para la ocasión pero como tenía (y sigue teniendo) amplios márgenes, se produjeron en él escasas mutilaciones significativas. Únicamente resultaron cortadas una de las numeraciones de folios, algunas notas marginales y adornos de una inicial del folio $11 \mathrm{v}$; y, como elemento más importante, los títulos de los documentos que sirvieron de modelo para la rúbrica, situados en la parte inferior de las páginas y que han desaparecido casi todos. Dos bifolios modernos de pergamino fueron usados como hojas de guarda.

El códice se encuentra en óptimo estado de conservación. Consta de 151 folios numerados en época actual. A partir del folio 7r, en el que comienza la reproducción de los documentos, aparecen tres numeraciones más, todas ellas modernas. Por otra parte, a lo largo de los amplios márgenes del cartulario se observan algunas notas, comentarios, signos de llamada, numeraciones de documentos e incluso algún cálculo de una data, que son pruebas de su utilización posterior con fines prácticos.

El f1r (lado pelo) estuvo adherido a una antigua encuadernación por lo que aparece muy oscurecido por diversas manchas. En él se aprecia ya el pautado a dos columnas y con mina de plomo característico del manuscrito. Se encuentra algo deteriorado por rotos, producidos posiblemente al despegarlo de su anterior encuadernación, y por picaduras de insectos comedores de cola, pues únicamente aparecen afectados por ellas el primero y el último folio del libro, precisamente los que estuvieron encolados y pegados a una tabla.

Los folios $1 \mathrm{v}$ y $2 \mathrm{r}$ oponen dos lados carne, iniciándose así una disposición que se mantendrá a lo largo de todo el volumen. En ellos se recoge (lámina $2, \mathrm{f} 2 \mathrm{r}, 1^{\mathrm{a}}$ columna) un documento copiado con posterioridad a la confección del manuscrito y aprovechando el pautado ya existente. Se trata de un diploma de Sancho IV, todavía infante, datado el 11 de mayo de 1282 y emitido en Valladolid. Su escritura es una letra de albaláes típica del XIII y de escasa cursividad, por lo que la copia no debió hacerse mucho más tarde de su emisión. Confirma este último dato un nuevo documento copiado en la 
segunda columna del folio 2r., del obispo García, datado el 9 de diciembre de 1289 y emitido en Sigüenza. Su escritura es completamente diferente a la del primero, una gótica diminuta, de tradición libraria, que aprovecha el pautado para introducir dos renglones en cada espacio destinado originariamente a una sola línea.

En el verso del f2 (lámina 3) comienza el índice de las escrituras que contiene el cartulario, que se extiende hasta el f6v. Cada documento aparece con un regesto en el que la letra inicial se copia fuera de la línea de justificación izquierda, en mayúscula y en tinta roja. Sin embargo, en ocasiones esta inicial miniada ha sido omitida. En los márgenes hay varios intentos de numeración de los documentos, en números romanos y árabes, ninguno de los cuales llega hasta el fin del índice.

Este índice, que es sin duda una guía eficaz para la utilización del manuscrito, está dividido en cuatro partes que son fiel reflejo de la estructura del archivo seguntino en el momento de la confección del cartulario. La primera se dedica a documentos reales ( $2 \mathrm{v}-3 \mathrm{v}$ ), un total de 46 , a los que se añade uno más cuyo resumen fue copiado en el siglo XVI aprovechando un espacio en blanco. El segundo grupo se dedica a los diplomas pontificios (f3v-4v), en total 43 escrituras mas una añadida en un espacio en blanco. Después se copiaron los regestos de 29 documentos episcopales (f4v-5v). El f6r se inicia con un espacio de 7 líneas en blanco, lo cual parece indicar que se pensaba rellenar el espacio con algún otro texto. Por último, figura un cuarto grupo de documentos particulares (f5v-6v) cuyos textos, como veremos, no fueron nunca copiados en el cartulario, con excepción de uno.

Además de reflejar la estructura del archivo seguntino, el índice es también una guía jerárquica, que da comienzo con los documentos de los reyes castellanos, máximos benefactores de la sede seguntina. En segundo lugar se encuentran los diplomas papales, pues los pontífices sólo beneficiaron a Sigüenza de forma escasa y desde la lejanía. Sus documentos suelen referirse a pleitos por términos con sedes contiguas, que incluso en ocasiones había perdido Sigüenza. Esto explica que estén relegados al segundo lugar. Finalmente se copió el grupo de documentos de los propios obispos y de los canónigos de la catedral, que se sitúan a sí mismos en un discreto tercer lugar. Pero los documentos del cuarto grupo del índice, emanados de autoridades laicas y particulares, ni siquiera llegaron a copiarse en el libro.

El f6v, originariamente casi vacío, fue rellenado con un nuevo diploma escrito con la gótico-libraria de módulo pequeño que antes mencionamos, y por la misma mano. Como en este caso, el texto sigue el pautado, 
insertando dos renglones en cada espacio destinado a una línea. El documento es del obispo García (1292, enero 31, Sigüenza).

En el folio 7r (lámina 1) comienza la reproducción de documentos, que finaliza en el 150v. Cada uno de ellos suele ir precedido del mismo título que aparece en los índices iniciales, rubricado en color rojo. En ocasiones sigue, en los diplomas reales, un magnífico crismón, en azul y rojo, con las letras alfa y omega (f24r, lámina 4). En la mayoría de los casos aparece también una inicial de gran tamaño, aunque variable, que alterna los mismos colores como ornamento principal (láminas 1, 4 y 5). Muchas veces pueden verse en ellas ambos colores, aunque sea en los motivos secundarios, y en muy escasas ocasiones aparecen hasta tres colores (los básicos mas negro, verde o naranja). Sigue a estos primeros elementos el texto de los documentos, a doble columna, y a veces en su final la reproducción de signos reales (láminas 4, 5 y 7), notariales o papales, junto al Bene Valete (f75v, lámina 6). Los testigos o confirmantes suelen aparecer dispuestos en columna con la inicial de sus nombres en rojo.

Llegando a la parte final, el f151r del códice reproduce tres breves documentos relativos a un juramento quinquenal que debía ser realizado por los clérigos de las iglesias de Santiago y San Vicente de Sigüenza ${ }^{13}$. Les sigue una transcripción en letra humanística de los dos primeros. Es importante para la datación del cartulario la copia de estos tres pequeños diplomas, sin duda alguna originales, que demuestran que el libro estaba ya concluido en 1255 .

Todas las hojas del cartulario miden aproximadamente 31,5 x 22,5 $\mathrm{cm}$. Sin embargo, no hay que olvidar que el códice fue guillotinado, por lo que éstas no son sus medidas originales, que serían algo más amplias. Al intentar comentar la disposición de los fascículos es necesario indicar que el excelente estado de la encuadernación ha dificultado el estudio de su composición, aunque la presencia de reclamos en gran parte del texto y la división en grupos definidos de los documentos han resultado muy útiles. Siguen en una tabla la estructura y algunas de las características codicológicas del manuscrito.

\footnotetext{
${ }^{13}$ Sus fechas son 2 de abril de 1255, 3 de mayo de 1264 y 26 de abril de 1269.
} 


\begin{tabular}{|c|c|c|c|}
\hline PARTE & CUADERNILLO & FOLIOS & RECLAMOS \\
\hline Índice de documentos & 1 binión & $1-4$ & \\
\hline $\begin{array}{l}\text { Índice de documentos, } \\
\text { hasta f6v. } \\
\text { Parte 1: Documentos rea- } \\
\text { les, desde el f7r }\end{array}$ & 2 cuaternio & $5-14$ & $14 \mathrm{v}$ iam \\
\hline \multirow{7}{*}{$\begin{array}{l}\text { Parte 1: } \\
\text { Documentos reales }\end{array}$} & 3 cuaternio & $15-22$ & 22v omnibus \\
\hline & 4 cuaternio & $23-30$ & 30v Garsia \\
\hline & 5 cuaternio & $31-38$ & 38v cartam (lámina 7) \\
\hline & 6 cuaternio & $39-46$ & 46v uel \\
\hline & 7 cuaternio & $47-54$ & $54 \mathrm{v}$ in (en tinta roja) \\
\hline & 8 cuaternio & $55-62$ & \\
\hline & 9 binión & $63-66$ & \\
\hline \multirow{6}{*}{$\begin{array}{l}\text { Parte 2: } \\
\text { Documentos pontificios }{ }^{14}\end{array}$} & 10 cuaternio & $67-74$ & $\mathrm{f} 74 \mathrm{v}$ sanctum \\
\hline & 11 cuaternio & $75-82$ & $82 \mathrm{v}$ pontificali \\
\hline & 12 cuaternio & $83-90$ & $90 \mathrm{v}$ totis \\
\hline & 13 cuaternio & $91-98$ & $98 \mathrm{v}$ presumunt \\
\hline & 14 cuaternio & $99-106$ & 106v uille \\
\hline & 15 cuaternio & $107-114$ & \\
\hline Añadido a la parte $2^{15}$ & 16 binión & $115-118$ & \\
\hline Parte 3: & 17 cuaternio & $119-126$ & $\mathrm{f} 126 \mathrm{v}$ in nomine \\
\hline
\end{tabular}

\footnotetext{
${ }^{14} \mathrm{f} 67 \mathrm{r}$, lámina 8 .
}

${ }^{15}$ En este añadido se recogen varios textos, copiados de forma irregular, con pautado y escrituras diversos a lo habitual. Parece haber sido confeccionado con posterioridad al resto de documentos. La lámina 9 muestra el f115v, en el que aparece la inicial más larga del códice. Los textos de este binión no figuran en el índice, salvo el primero, cuyo título se copia en un espacio originariamente en blanco. 


\begin{tabular}{|l|l|l|l|}
\cline { 2 - 4 } Documentos episcopales & 18 cuaternio & $127-134$ & $\mathrm{f} 134 \mathrm{v}:$ ualet $^{16}$ \\
\cline { 2 - 4 } & 19 cuaternio & $135-142$ & \\
\cline { 2 - 5 } & 20 cuaternio & $143-150$ & \\
\cline { 2 - 4 } & 21 folio & 151 & $\begin{array}{l}\text { último folio del cartula- } \\
\text { rio }\end{array}$ \\
\hline $\begin{array}{l}\text { La cuarta parte, de docu- } \\
\text { mentos particulares, no }\end{array}$ & & & \\
\hline
\end{tabular}

La encuadernación del cartulario ha contribuido a la desaparición de gran parte de las perforaciones marginales. Sin embargo, a través de las que aún pueden verse, podemos reconstruir el esquema de los orificios, que se efectuaron sobre cada bifolio, posiblemente de forma individual. Los instrumentos utilizados fueron un compás o un punzón, que producen orificios circulares, en ocasiones irregulares y en otras algo alargados. En los márgenes extremos, izquierdo y derecho, aparecen 24 orificios, que corresponden a idéntico número de líneas de texto existentes en cada página. En los márgenes superior e inferior de cada folio se hicieron cuatro perforaciones que sirven de unión a las líneas de justificación. En el último cuadernillo las perforaciones se realizaron más centradas de lo habitual, por lo que no resultaron guillotinadas y son perfectamente visibles.

Más abajo hemos reproducido en gráficos el esquema de las perforaciones junto con el del pautado. Éste ha sido trazado con mina de plomo sobre todas las páginas del cartulario con una gran regularidad. Consta de 24 líneas rectrices, separadas entre sí por $9 \mathrm{~mm}$. Las dos columnas de que consta cada página están flanqueadas por cuatro líneas de justificación. La caja de escritura que queda formada consta de dos columnas, cada una de $6 \mathrm{~cm}$. de anchura, con $1,5 \mathrm{~cm}$. de intercolumnio. La escritura, de gran módulo, normalmente no respeta demasiado la justificación y la sobrepasa constantemente.

El formato del códice es rectangular y las proporciones entre lado largo/corto $(31,5 / 22,5 \mathrm{~cm}$.) de una hoja arrojan un cociente de 1'4, cifra cercana

\footnotetext{
${ }^{16}$ Puede observarse que los reclamos suelen aparecer de forma regular al inicio de cada uno de los tres grupos de documentos pero faltan al final. Da así la impresión de que los últimos fascículos de cada grupo fueron añadidos al cuerpo del cartulario en un momento posterior. El reclamo se sitúa siempre bajo la segunda columna de cada folio.
} 
al double Pythagore de L. Gilissen (1'5). La escritura está dispuesta a dos columnas. Cada una mide 21,5 x $6 \mathrm{~cm}$. Los márgenes externos de los folios son mucho más amplios que los internos. Sus medidas y todas las demás de un folio tipo recto y de uno verso, pautado y perforaciones quedan reflejadas en los gráficos aludidos, en las que se expresan en centímetros.

En ocasiones se han conservado en la parte inferior de los folios los títulos de los documentos (lámina 10) que fueron copiados en rojo por el encargado de la rúbrica. Su texto es idéntico al que aparece en el índice del cartulario, con ligeras variantes ortográficas. La encuadernación ha cortado sin embargo la mayoría de estos textos ${ }^{17}$, por lo que son pocos los que son completamente legibles (f10v, 25v, 89r).

La tinta habitual empleada es negra, muy brillante en general aunque a veces clarea. Hay algunos documentos escritos en tinta marrón, los añadidos después de la primera etapa de la copia. Se utiliza con profusión la tinta roja, cuestión sobre la que volveremos al comentar la ornamentación.

Se observan dos tipos de pergamino a lo largo del cartulario. En unos folios aparece una piel gruesa y recia, que resulta difícil doblar, y en otros un tipo más sutil, delgado y suave, que en algunos casos transparenta, por ejemplo el f137.

${ }^{17}$ Quizás la función de estos textos fuera precisamente el desaparecer en el momento de la encuadernación. 


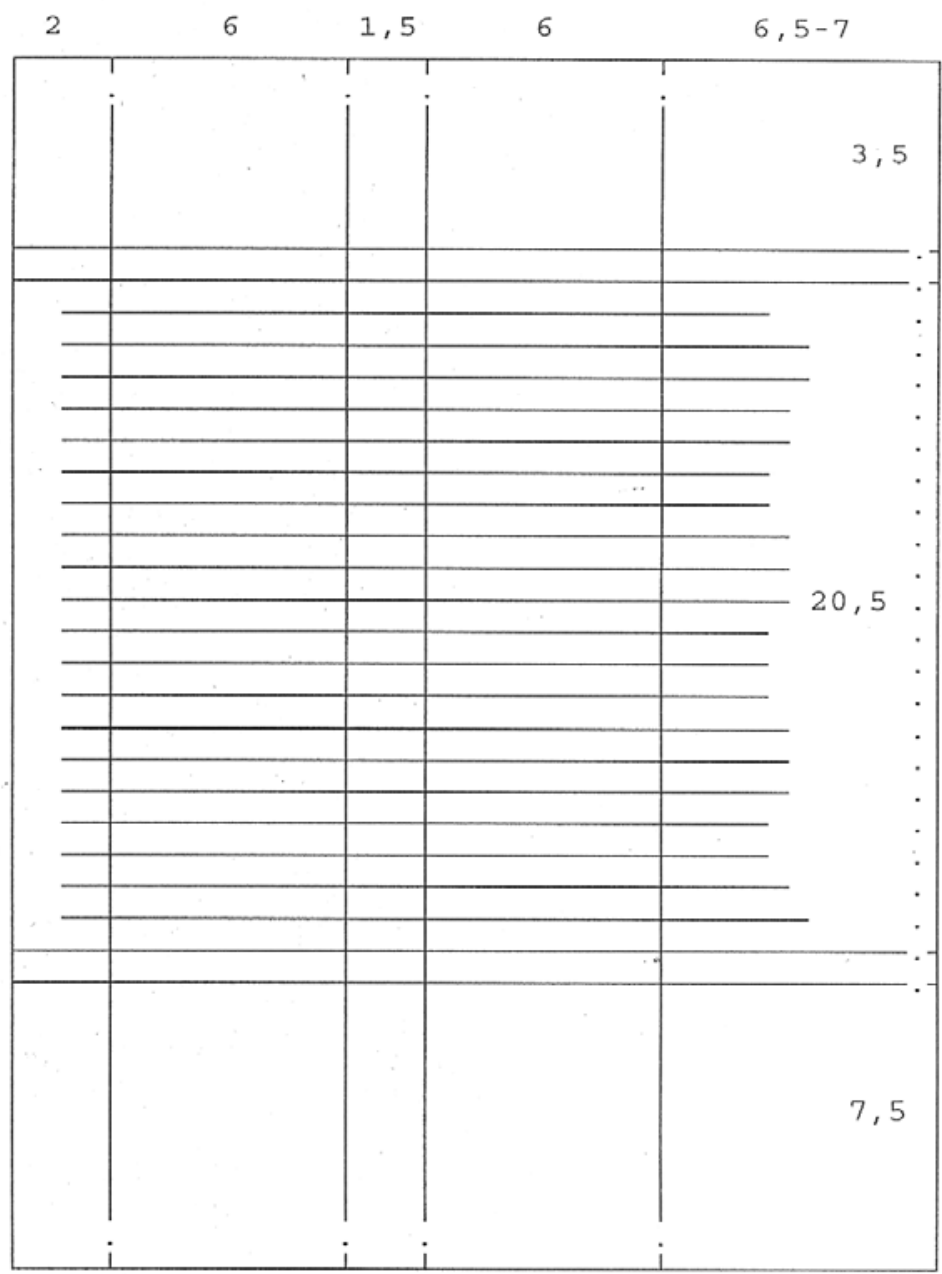

PAUTADO Y PERFORACIONES: RECTO 


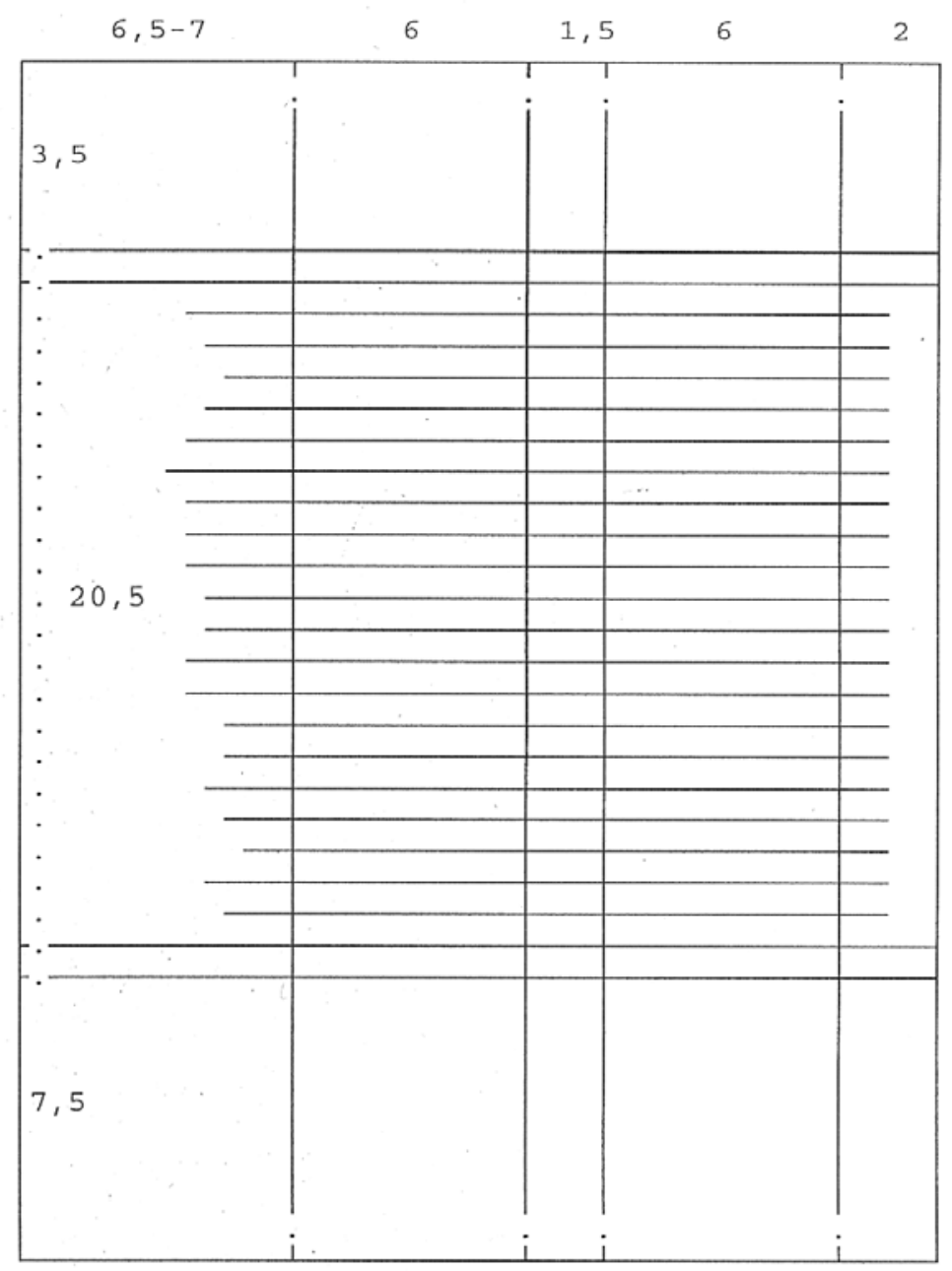

PAUTADO Y PERFORACIONES: VERSO 
Otro aspecto de interés es el proceso de elaboración del códice. Como es habitual, lo primero que se plasma sobre las hojas del cartulario es el pautado. A continuación hizo su trabajo el copista principal, encargado de la copia de los textos de los documentos, dejando los oportunos espacios para títulos, iniciales adornadas, crismones, signos y demás elementos decorativos. Este mismo copista apuntaba en el margen inferior, en una gótica libraria de pequeño módulo, los títulos de los documentos y es el encargado de calcular el espacio a dejar en blanco para copiar en él más tarde el título en rojo. De hecho en muchas ocasiones se equivoca y el rotulista tiene que escribir al margen, tiene que alargar de manera exagerada la forma de las letras, o se ve obligado a rellenar el espacio sobrante con líneas rojas de cancelación. Antes de títulos, iniciales rojas y otros elementos decorativos se copian los signos reales, notariales y papales con sus Bene Valete. Finalmente, el rotulista copia todos los elementos decorativos: crismones, grandes y pequeñas iniciales, $\mathrm{y}$ títulos de los documentos.

Otras cuestiones sobre las que se puede verter más luz son la datación y las etapas de confección del códice. A través de su escritura y de las fechas de sus documentos podemos deslindar una primera etapa, en la que se copia el grueso de los diplomas, los más tardíos de los cuales son de los años 1207 y 1212. En este momento se debió confeccionar el cartulario. La iniciativa fue sin duda debida al obispo Rodrigo (1192-1221), que buscaría de esta forma perpetuar su memoria como bienhechor de la institución catedralicia. ${ }^{18}$ Es posible identificar una segunda etapa por medio de los documentos copiados por manos diferentes a las habituales, aunque con escrituras en la práctica coetáneas. En este momento, que es anterior a 1250, se añade también un fascículo (binión n1 16), necesario para insertar los nuevos diplomas, que se copian en letra y tinta diferentes. En una tercera etapa, en la segunda mitad del siglo XIII, se aprovechan los espacios que habían quedado en blanco en determinados folios para copiar nuevos diplomas, que se distinguen con facilidad a simple vista por su escritura diferente.

\footnotetext{
${ }^{18}$ Conviene mencionar que en el libro se han incluido, en el tercer grupo de documentos, numerosos diplomas expedidos por este prelado, que ocupó la sede hasta 1221 . 


\section{LA RAZÓN DE SER DEL CARTULARIO}

Vistas estas últimas cuestiones formales del códice es necesario volver sobre la estructura de su contenido textual. Ciertamente no se trata de una mera cartoteca, a imagen de lo que podrían ser los fondos en microfilm o CdRom que atesoran nuestros archivos. El cartulario seguntino no responde simplemente a cuestiones archivísticas de clasificación sino que se integra en un proyecto programático de su promotor, el obispo don Rodrigo, como trataremos de explicar. Para comprender este proyecto ha sido necesaria la prospección codicológica del libro que precede.

Según Ruiz Asencio ${ }^{19}$ los cartularios hispanos separan habitualmente documentos reales, pontificios, episcopales y particulares, que a su vez pueden dividirse por dominios señoriales. Esta estructura se repite fuera de la península con ciertas variantes ${ }^{20}$. En nuestra opinión esta norma se alterna con otra, que organiza los códices diplomáticos por zonas geográficas, como sucede en los tumbos de Celanova y Sobrado. Por lo que respecta al cartulario seguntino, su estructura interna está muy clara. Se divide en cuatro grupos que dependen de la categoría de sus emisores: diplomas reales, pontificios, episcopales y diplomas particulares. Éstos últimos sin embargo no fueron copiados en el cartulario, como se ha dicho. Esta estructura es fiel reflejo del estado del archivo y de los intereses del archivero y de sus superiores, en particular del obispo.

En este sentido, es necesario abordar uno de los aspectos de mayor interés del cartulario, su razón de ser, cuestión a la que dedicaremos la parte final del trabajo. Tradicionalmente se han dado razones de tipo utilitario para explicar la confección de cartularios. Por ejemplo, para evitar frecuentes pérdidas que se producirían por descuidos, incendios, saqueos o robos, o para no manipular y estropear los originales. Sin ser cuestiones despreciables, como veremos, no son suficientes para justificar el nacimiento de la mayoría

\footnotetext{
${ }^{19}$ José Manuel RuIZ ASENCIO, voz Cartularios, en el Diccionario de Historia Eclesiástica de España, I, pp. 368-370.

${ }^{20}$ Noëlle DeFLOU-LECA, L'élaboration d'un grand cartulaire au XIIIe siècle: le cas de SaintGermain d'Auxerre, «Revue Mabillon», 8/69 (1997), p. 197, da para los cartularios franceses la siguientes estructuras: por orden geográfico con las posesiones divididas por regiones, clasificación por dominios, según el estatuto jurídico de las actas, y orden temático.
} 
de estos libros, que habitualmente no tienen una sola sino varias razones de ser.

Los cartularios son un fenómeno europeo que aparece hacia el siglo $X$ pero que se generaliza en los dos siguientes ${ }^{21}$. Su elaboración se engloba en un movimiento reformador consistente en la ordenación y sistematización de los beneficios eclesiásticos para intentar hacer frente a las usurpaciones laicas $^{22}$. En la península ibérica es constante la legislación conciliar que intenta evitarlas, aunque su continuidad es también prueba de su ineficacia ${ }^{23}$. El siglo XIII se puede considerar el siglo de oro de estas compilaciones, pues en él se produce un aumento considerable de la producción escrita en todos los ámbitos, tanto los eclesiásticos habituales como los laicos. Por lo que respecta al caso hispano, se ha hablado, como posible origen de los cartularios, de la ilegibilidad de la escritura visigótica de los pergaminos originales por los clérigos de los siglos XII y XIII, y de la inestabilidad política de los reinos castellano y leonés, que aconsejaba hacer una copia de seguridad de los pergaminos sueltos.

El primero de los grandes cartularios hispanos, el Liber Testamentorum, de la catedral de Oviedo ${ }^{24}$, se elabora entre 1109 y 1112 . Está escrito en visigótica, por lo que la causa de su confección debió de ser más bien la segunda de las aludidas, pues a la muerte de Alfonso VI (1109) el reino castellano-leonés pasa por una etapa muy inestable que coincide con la aparición de los primeros cartularios peninsulares. Otro caso es el llamado Tumbo A de la catedral de Santiago, cuya confección puede datarse en 1129. En su prólogo se alude tanto a la ilegibilidad de las escrituras como a la pérdida de las mismas para justificar la elaboración del libro. Pero parece claro que también influye en ella el deseo de ostentación de la sede compostelana, que mediante los adornos y miniaturas que presenta este códice, pretende mostrar la grandeza y riqueza de la nueva dignidad arzobispal que había sido

\footnotetext{
${ }^{21}$ Una de las pocas obras de conjunto que existen sobre los cartularios es: Les cartulaires. Actes de la Table ronde organisée par l'Ecole nationale des chartes et le GDR 121 du CNRS, Paris, 5-7 décembre 1991, réunis par Olivier Guyotjeannin, Laurent MORELLE et Michel PARISSE, Paris, 1993

${ }^{22}$ Deflou-LeCA, p. 198.

${ }^{23}$ Véase al respecto lo que decimos en la nota 33.

${ }^{24}$ Recientemente editado por J.A. VALDÉS GALLEGO, El Liber testamentorum Ovetensis. Estudio filológico y edición, Oviedo, BIDEA, 1999. 
dotada pocos años antes, en $1120 .{ }^{25}$ Estas y otras razones explican también la elaboración del cartulario de Sigüenza.

Otro conocido prólogo nos sumerge en el origen de muchos cartularios, la utilidad, la seguridad y la conservación de la memoria:

Personalmente expresasteis el deseo de que todos los documentos de vuestro reinado y de vuestros antecesores se reunieran en un volumen tanto para la utilidad de los súbditos y guarda de sus derechos como para eterno recuerdo de los acontecimientos más memorables.

Se trata de la introducción del Liber Feudorum Maior, confeccionado a fines del siglo XI por Ramón de Caldes, deán de la iglesia de Barcelona, por encargo del rey Alfonso el Casto ${ }^{26}$. Y este preámbulo es aplicable a la perfección al cartulario seguntino.

\section{Utilidad}

En primer lugar, sus documentos se reúnen en un solo volumen, lo cual facilita la localización y empleo de escrituras del archivo y permitiría un mejor funcionamiento de la institución. Las muchas anotaciones marginales que suele haber en los cartularios hispanos prueban que eran libros que se utilizaban constantemente. Este uso podía convertirse en exclusivo, de forma que los pergaminos originales se descuidaban, se olvidaban y se perdían. Así sucedió en muchos casos, como en los tumbos A de Santiago, de Celanova y de Sobrado, pero no en otros, como en la catedral de León, donde se han conservado muchos de los originales. Es excepcional el caso del monasterio

\footnotetext{
${ }^{25}$ Manuel C. DÍAZ y DíAZ, Los Tumbos de Compostela, Madrid, Edilán, 1985, pp. 16-18. Este cartulario ha sido editado por Manuel LuCAS ÁLVAREZ, La documentación del Tumbo A de la catedral de Santiago de Compostela. Estudio y edición, León, 1997 (Fuentes y Estudios de Historia Leonesa, 64).

${ }^{26}$ Francisco MiQuel Rosell, Liber Feudorum Maior. Cartulario real que se conserva en el Archivo de la Corona de Aragón, Barcelona, 1945. El párrafo completo que citamos dice así en el texto latino original (p. 1): «Huius igitur fidei rectitudine ductus, sepenumero inter alia grandia et ardua, divina instillante gratia, viva expressistis voce, vos habere votum et desiderium ut omnia instrumenta propria et inter vos vestrosque antecessores ac homines vestros confecta et in ordinatione confussa, sub uno redigerentur volumine, tum propter subiectorum scilicet utilitatem, ut his instrumentis ad memoriam revocatis, unusquisque ius suum sortiatur, tum propter eternam magnarum rerum memoriam, ne inter vos et homines vestros, forte oblivionis occasione, aliqua questio vel discordia posset oriri».
} 
santiagués de San Martín Pinario, situado junto a la catedral, que nunca tuvo cartulario. En su lugar se confeccionaron, a finales del siglo XVI, los llamados "mazos" de diplomas originales, unos libros de gran tamaño sujetados por anillas a los que los pergaminos se añadían pegados o cosidos a grandes hojas de grueso papel. El monasterio tuvo 180 mazos, cada uno con 20 ó 25 piezas, que se mantuvieron íntegros hasta la desamortización acaecida en $1840^{27}$.

Pero la utilidad buscada se demuestra también por el orden interno del manuscrito: no solo se busca reunir los documentos en un libro manejable, sino algo más. Se trata de un libro dotado de un índice de los diplomas que contiene, que se numeran, y estructurado en las cuatro partes en que está dividido. Ha sido redactado a dos columnas y cada documento va precedido de un título escrito en tinta roja, diferente a la normal que tiene un fuerte efecto visual. Además cuenta con iniciales ornamentadas que alternan los colores rojo y azul, produciendo así una atracción patente, y existe también una jerarquía de mayúsculas en rojo de diferentes tamaños. En definitiva, este tipo de libros está pensado todo él al statim invenire, a encontrar en él con facilidad cualquier parte de su contenido ${ }^{28}$.

El cartulario seguntino sigue por tanto el modelo de los libros universitarios nacidos en París, Bolonia y Oxford, cuyo fin es el estudio y la consulta. En ellos era necesario poder encontrar con facilidad cualquier parte de su contenido, hecho que constituye su primer objetivo. Son libros bien organizados que tienen como fin la guarda del saber más alto de la época y la fácil consulta de sus textos. Su escritura suele ser gótica o semigótica y se confeccionan en pergamino. Las dos columnas dejan un cierto espacio en blanco y facilitan la localización del contenido. Esta forma de estructurar la página escrita, mediante la subdivisión del texto en dos partes o columnas, mejora también la legibilidad. En definitiva, este modelo es una nueva concepción de la página escrita, que se desarrolla desde el siglo XIII. Consiste en el uso de una serie de medios auxiliares, útiles para agilizar la lectura y consulta del libro, que inciden de manera directa en la apariencia del texto conservado.

\footnotetext{
${ }^{27}$ Para una descripción de los mazos ver: Carlos Sáez, Ma del Val GonZÁlEz DE LA PEÑA, La Coruña. Fondo Antiguo (788-1065), 1, Universidad de Alcalá, 2003, pp. 12-13 y 24.

${ }^{28}$ Guglielmo CAvallo, Cultura scritta e conservazione del sapere: dalla Grecia Antica all'Occidente medievale, en P. ROSSI (ed.), La memoria del sapere, cit., pp. 29-67.
} 
Sin embargo es necesario matizar esta opinión, pues pensamos que el libro seguntino conserva una fuerte tradición altomedieval. Su ornamentación es remarcable, por lo cual no es del todo un libro utilitario, sino un librotesoro como otros muchos altomedievales ${ }^{29}$, con una finalidad de ostentación del comitente, como más abajo comentaremos. Por tanto, algunos de sus elementos sirven para ambos fines, utilidad y ostentación: las iniciales que alternan rojo y azul sirven tanto para uso y facilidad de búsqueda como para crear un libro lujoso. Por otra parte, y a diferencia de otros cartularios hispanos, no ha sido casi usado ${ }^{30}$, pues sus márgenes se conservan intactos y en muy buen estado. Las anotaciones que hay son más bien escasas y la inmensa mayoría modernas, de los siglos XVI al XVIII. Es por tanto un libro destinado a perpetuar el saber pero no para ser consultado, mientras que los nuevos libros que nacen al calor de las universidades son libros para ser leídos y para transmitir su contenido ${ }^{31}$. Los centros eclesiásticos de la alta edad media se limitan a custodiar los libros pero el nuevo libro escolástico conserva, transmite y divulga el saber. El cartulario seguntino se encuentra por tanto entre ambos conceptos.

Es por tanto un libro en el que se ha buscado una doble utilidad. En primer lugar, crear un libro de tamaño manejable que facilite el uso del archivo evitando búsquedas y la utilización de los pergaminos sueltos. Y, en segundo lugar, crear un libro con un claro orden interno para buscar en él datos y para hallarlos con facilidad. Y todo ello con el fin de resultar útil a la institución a la que sirve.

\section{Guarda de los derechos}

En segundo lugar, el cartulario seguntino se confecciona para guarda de los derechos de canónigos y obispos de la catedral, es decir, con un fin jurídico, para afianzar y demostrar prerrogativas y dominios adquiridos. La copia en cartularios por los monjes hispanos de los siglos XII y XIII de

${ }^{29}$ Franco ALESSIO, Conservazione e modelli di sapere nel Medioevo en La memoria del sapere. Forme di conservazione e strutture organizzative dall'antichità a oggi, a cura di Pietro ROSSI, Roma-Bari, Laterza, 1988, pp. 104-5.

${ }^{30} \mathrm{El}$ tumbo de Celanova, por ejemplo, tiene infinidad de anotaciones marginales y fue tan utilizado que ya en el siglo XVIII sus márgenes estaban deteriorados y tuvieron que ser restaurados por los monjes.

${ }^{31}$ Alessio, ob. cit., p. 107. 
documentos en escritura visigótica tiene este mismo fundamento. No es extraño que sea en estos siglos cuando aparecen estos libros, precisamente en un momento en el que interesa tener controladas mediante escrituras las propiedades y derechos de una determinada persona o institución. Ahora no sólo se es propietario por el hecho de trabajar y controlar una determinada tierra, además hay que demostrar su dominio por escrito.

Esta búsqueda de seguridad es necesaria por la inestabilidad política de los reinos castellano y leonés, que aconsejaba hacer una copia de seguridad de los pergaminos sueltos. José Rius es consciente de que los cartularios comienzan a proliferar en la península en el siglo XIII y lo explica precisamente por esta razón. En los siglos X y XI las posesiones eclesiásticas habían sufrido poco acoso de reyes y nobles. Pero al crecer tanto el poder real, los nuevos municipios como el feudalismo laico, éstas propiedades, no siempre bien delimitadas, comenzaron a ser disputadas y surgió la necesidad de copiar en volúmenes los títulos originales, quizás para emplear éstos como prueba en los pleitos ${ }^{32}$. Y de hecho es constante la alusión a las usurpaciones de bienes de la Iglesia por parte de señores laicos en los concilios de esta época. En las reuniones celebradas en León 1017 y Coyanza 1055 se emitieron leyes de protección de bienes eclesiásticos ${ }^{33}$. El aumento en la producción de documentos y de cartularios es prueba evidente de su necesidad. Y el Registro de Corias, elaborado en 1207, tiene precisamente este origen: un intento de usurpación del propio rey Alfonso XI y de sus oficiales de bienes del monasterio de Corias ${ }^{34}$.

\section{La conservación de la memoria}

En tercer lugar, se alude en el preámbulo reproducido al "eterno recuerdo de los acontecimientos más memorables”. Aquí entra en juego una

\footnotetext{
${ }^{32}$ José Rius, Cartulario de Sant Cugat del Vallés, Barcelona, 1945, vol. I, p. IX.

${ }^{33}$ Amancio IsLa FreZ, La alta edad media, siglos VIII-XI, Madrid, 2001, pp. 98, 112 y 250. Y entre otros legislan sobre lo mismo los concilios de Barcelona 1131, León 1114 y 1135 : Diccionario de Historia Eclesiástica de España, I, sub voce Concilios, Madrid, 1972.

${ }^{34}$ Editado por Alfonso GARCía LEAL, El Registro de Corias, Real Instituto de Estudios Asturianos, Oviedo, 2000. El rey pleitea contra el monasterio reclamándole el pedido y pretendiendo el señorío sobre el mismo, pero su abad Suero acudió para su defensa con el Registro a las cortes de Toro, donde la sentencia le fue favorable. 
palabra clave, la memoria conservada por escrito, que nos lleva a una más completa explicación de la razón de ser del libro seguntino.

Es necesario evocar aquí una triple memoria. En primer lugar, la memoria de las donaciones recibidas por la iglesia seguntina, que hay que preservar para el futuro. Una copia de seguridad de las escrituras siempre es beneficiosa pues éstas pueden ser robadas o se pueden perder, hechos que la documentación medieval menciona con relativa frecuencia. Por tanto, conviene preservar la memoria de los documentos recibidos por cabildo y obispo. De hecho, los documentos a incluir en el cartulario se escogen, no están en él todos los del archivo, por lo que se busca un fin conmemorativo de los elegidos. Se copian, por tanto, los más valiosos a la vista de obispo y canónigos.

Pero, en segundo lugar, tampoco hay que olvidar la memoria de los donantes, de los bienhechores de la catedral que le cedieron derechos y posesiones pro remedio anima y a cambio de la celebración de oficios divinos. En cierta manera este hecho acerca el cartulario seguntino a algunos obituarios o libros de difuntos.

$\mathrm{Y}$, en tercer lugar, el cartulario también preserva la memoria de sus obispos y de su administración de la vida catedralicia, en especial de su más directo responsable, el obispo Rodrigo, como veremos. Así adquiere también algo de gesta episcoporum y dedica a sus obispos una de las tres partes de diplomas que fueron copiadas en el libro. Y además, en las hojas que quedaron originariamente en blanco, fueron añadidos nuevos documentos episcopales, junto con uno real. En cambio, los bienhechores menores, que dieron origen a documentos privados, no merecieron que su memoria se conservara en el libro, aunque su presencia en el índice por lo menos denota una cierta intención inicial de conmemorar los favores otorgados a la institución.

\section{Ostentación}

Utilidad, orden, seguridad, conservación y conmemoración quedan así testimoniados. Pero queda tratar de la ostentación. El encumbramiento de los obispos seguntinos es un hecho palpable a lo largo del siglo XII y de los primeros años del XIII, época que nos interesa. Siempre estuvieron en el lugar acertado y en el momento preciso: conquista de Cuenca (1177), batallas de 
Alarcos (1195) y de Las Navas de Tolosa $\left(1212^{35}\right)$ y sus relaciones con el poder central fueron siempre buenas, como lo prueba la abundante documentación real existente en el archivo catedralicio. Pero prescindiendo de cuestiones generales de tipo político y coyuntural ${ }^{36}$, que sin duda movieron al obispo Rodrigo a dar una etapa positiva por concluida y a conmemorarla con la confección del cartulario, la ostentación también aparece apoyada por la riqueza ornamental del códice, uno de los más destacados de la catedral desde esta óptica (lámina 11, una de las iniciales más bellas). En sus páginas se concentran numerosas iniciales, algunas tan largas como una columna de texto, y crismones en los que se van alternando azul y rojo como colores dominantes. Todos estos elementos están además adornados con motivos vegetales y en una $\mathrm{P}$ mayúscula se aprecia una cara humana, aunque este único detalle antropomorfo es poco significativo (lámina 12). Hay otros adornos en varios colores, como el título con que se inicia el bloque de documentos pontificios (lámina 8), y también en tinta roja, sobre los que obviamos volver pues han sido mencionados más arriba.

Esta profusión de color se completa con la frecuente presencia de signos validatorios de gran tamaño. Estos elementos se reproducen en los cartularios debido al valor que ostentan representando a sus emisores. Como expuso Peter Rück ${ }^{37}$, el documento tiene un poder propagandístico y placativo. Y cuando se copia en cartularios sus signos, los elementos esenciales destinados a llamar la atención visual, se reproducen en ellos y a veces, como en el caso que nos ocupa, se exagera su tamaño. Todo ello va además acompañado de amplios márgenes, que son una nueva prueba de ostentación pues el desperdicio de pergamino sólo estaba al alcance de unos pocos.

Por tanto, nos hallamos ante un libro suntuoso aunque no haya en él miniaturas comparables a las del Tumbo A de la catedral de Santiago, del Liber Testamentorum de Oviedo, del tumbo del monasterio de Toxos Outos o del Libro de las Estampas de la catedral de León, cartularios emblemáticos,

\footnotetext{
${ }^{35}$ Pudiera ser significativa esta fecha, que coincide con la del documento más tardío de la primera etapa de confección del cartulario.

${ }^{36}$ De ellas se han ocupado otros autores. Entre ellos A. UBIETO, Los primeros años de la diócesis de Sigüenza, en «Homenaje a J. Vincke», Madrid, 1962-1963, pp. 135-149; y la obra ya clásica de Toribio Minguella y ARNEDo, Historia de la diócesis de Sigüenza, cit.

${ }^{37}$ Peter RÜCK, Die Urkunde als Kunstwerk, en Begegnung des Ostens und Westens um die Wende des ersten Jahrtausend, Köln, 1991, pp. 311-333. Sobre esta cuestión aplicada a los privilegios rodados hispanos puede verse Carlos SÁEZ, Documentos para ver, documentos para leer, «Anuario de Estudios Medievales», 29 (1999), pp. 899-915.
} 
entre otros, de los archivos españoles. Sólo hay en la catedral seguntina un libro que se asemeje en estas características al cartulario, el códice designado con el número 8, que debió ser obra del mismo comitente, el obispo Rodrigo. Hay otros muchos manuscritos con iniciales adornadas, algunas de gran tamaño, incluso de época humanística, pero ninguno comparable al que nos ocupa.

\section{El obispo don Rodrigo}

Sin menospreciar los factores citados hasta aquí en la elaboración del presente cartulario, también se debe dar el papel que se merece a la memoria que quiso dejar a la posteridad don Rodrigo, a la hora de promover su creación. Éste obispo se sabe inferior frente a las figuras de sus predecesores. No olvidemos que Bernardo de Agen, además de primer obispo de la diócesis fue canciller y capellán de Alfonso VII; Cerebruno, tutor de Alfonso VIII y arzobispo de Toledo, tras abandonar Sigüenza; y su más inmediato predecesor, San Martín de Finojosa, fue uno de los primeros abades del monasterio de Santa María de Huerta y muy cercano a la curia pontificia. Don Rodrigo, aunque personaje notable también en su momento gracias a su participación en batallas tan importantes como las de Alarcos y las Navas de Tolosa, no alcanza la categoría de sus predecesores.

Durante su prelatura la reconquista ya había concluido prácticamente en su entorno, por lo que Sigüenza pierde su valor estratégico y la posibilidad de aumentar territorios a costa de los musulmanes. Una vez limitada la expansión exterior, los ojos de don Rodrigo se vuelven hacia el interior de su diócesis y comienzan a mediar en disputas, internas o con diócesis contiguas, en las que el obispo aparece ya sea como parte implicada o como juez. Es precisamente en esta parte donde está más latente esta idea, ya que nos presenta a un obispo benefactor, protector y regulador de las instituciones que componen la diócesis así como de su cabildo ${ }^{38}$.

En este sentido, es significativo el número de documentos del cartulario que tienen al obispo Rodrigo como protagonista, lo que viene a redundar en la intención subyacente del libro, la conmemoración de la figura

\footnotetext{
${ }^{38}$ Almudena E. GUTIÉRREZ GARCÍA-MuÑoz, Originales y copias: la conservación en el Archivo de la Catedral de Sigüenza (siglo XII), «VI Congreso Internacional de Historia de la Cultura Escrita», vol. 2, Madrid, Calambur Editorial, 2002, pp. 133-142. 
de su impulsor. En el tercer grupo de documentos descubrimos a un don Rodrigo protagonista de muchos de ellos que lo señalan como benefactor de su diócesis.

Además el cartulario supone la afirmación de los derechos de la diócesis y la confirmación de su fuerza y éxito. Su elaboración se produce en un tiempo de afirmación de la sede, a la manera de los gesta episcoporum o abbatum, que suelen tener su origen en momentos de reforma o en momentos de afirmación del poder de prelados y abades que los mandan escribir. Y como dice Miquel Rosell, un cartulario no es más que la expresión gráfica del incremento interno, en tierras y poderío, de la institución a que se refiere ${ }^{39}$. Con el auxilio, probablemente del archivero-bibliotecario de la catedral, se condensan su biblioteca, archivo y en definitiva la memoria de su iglesia, en un libro manejable y de fácil consulta, donde todo se encuentra con facilidad, y que a la vez es un instrumento defensivo y ofensivo eficaz ${ }^{40}$.

En definitiva, el cartulario seguntino del siglo XIII es una obra de exaltación de la identidad de don Rodrigo, de su sede y de sus obispos. Por otra parte es un archivo abreviado de sus escrituras más emblemáticas, valiosas y significativas. Y en todo caso, el libro no es producto del azar sino de un plan bien concebido por el obispo Rodrigo ${ }^{41}$.

\footnotetext{
${ }^{39}$ Francisco MIQUEL Rosell, Liber Feudorum Maior, Barcelona, 1945, I, p. XVII.

${ }^{40}$ Michel Sot, Gesta episcoporum, gesta abbatum, Turnhout, 1981, Tipologie des sources du moyen age occidental, $\mathrm{n}^{\circ} 37, \mathrm{p} .39$

${ }^{41}$ Como suele suceder, siempre quedan en el tintero temas a tratar. Por ejemplo, si el cartulario forma parte de un proyecto más amplio o un estudio de la estructura interna de cada una de las tres partes que lo componen. Asimismo hay un episodio que pudo tener alguna relación con la elaboración del cartulario, el presunto homicidio por don Rodrigo de uno de sus feligreses en un tumulto acaecido en la catedral durante la celebración de oficios divinos, carga de la que el prelado fue liberado por bula pontificia. Véase al respecto Demetrio MANSILLA, La documentación pontificia hasta Inocencio III (965-1216), Monumenta Hispaniae Vaticana, Sección Registros, vol. 1, Roma, Instituto Español de Estudios Eclesiásticos, 1955, documentos $\mathrm{n}^{\text {os }} 412$ y 413 , ambos de 1209 , noviembre 24 .
} 


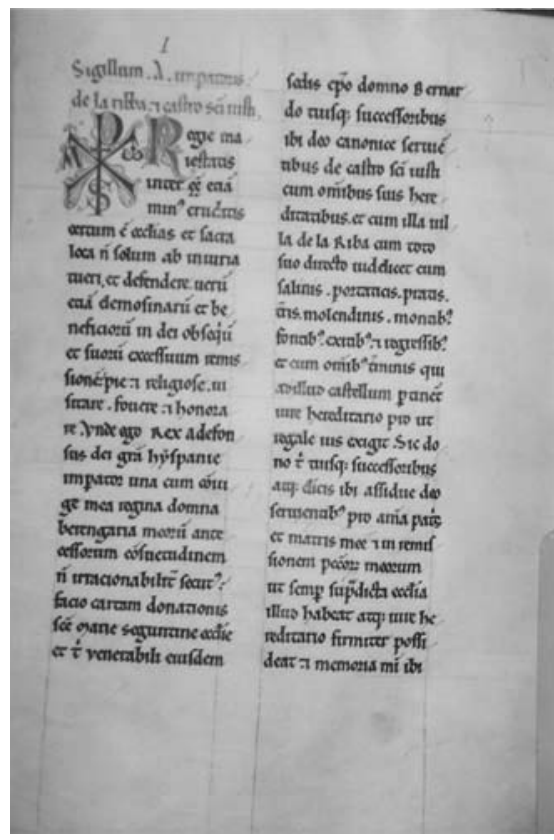

Lámina 1. Fol. 7 v.

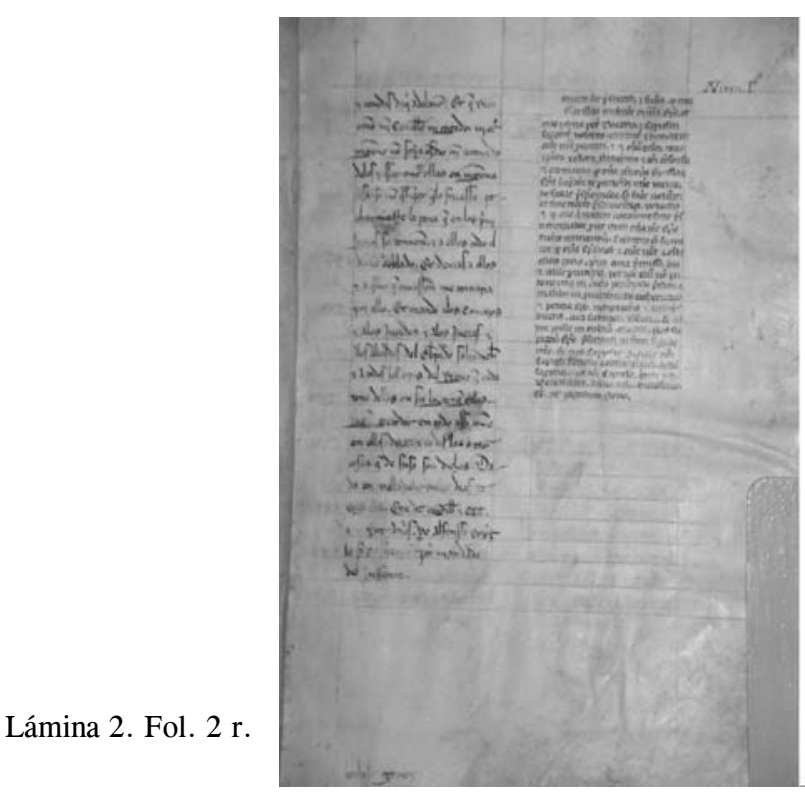

ANUARIO de Estudios MedieVales (AEM) — 36/1, 2006 ISSN 0066-5061. 


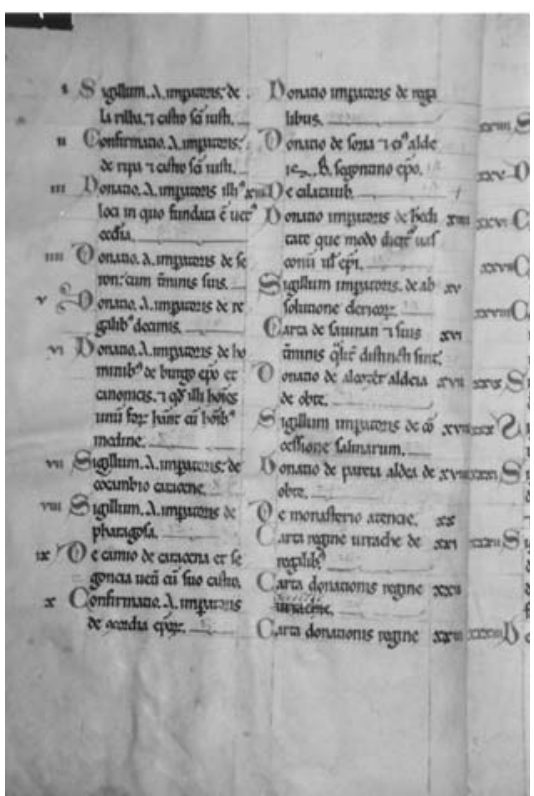

Lámina 3. Fol. 2 v.

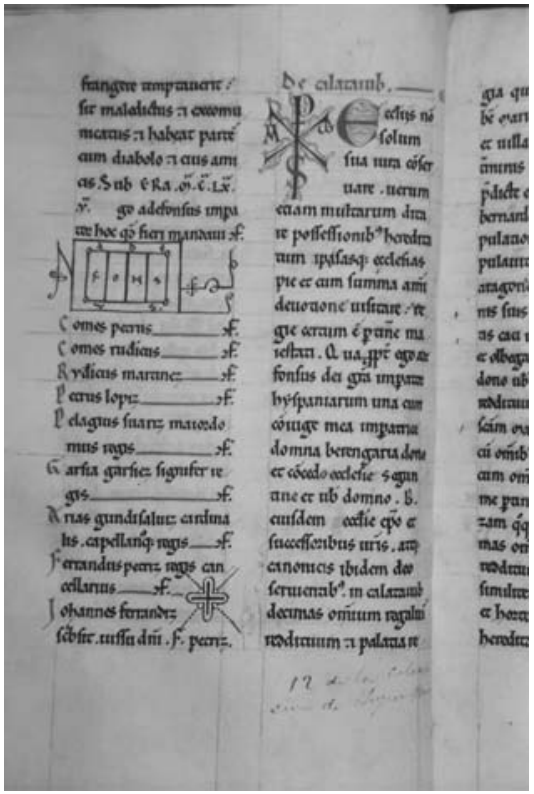

Lámina 4. Fol. 24 v. 


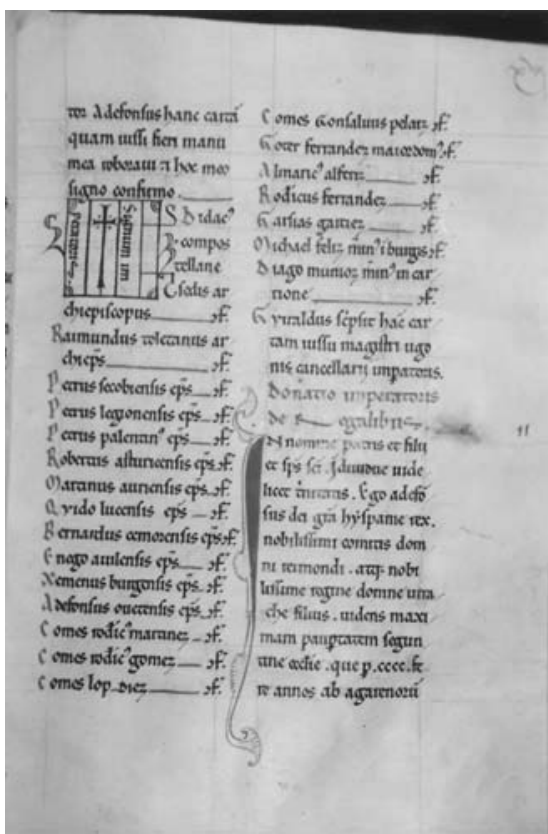

Lámina 5. Fol. 22 r.

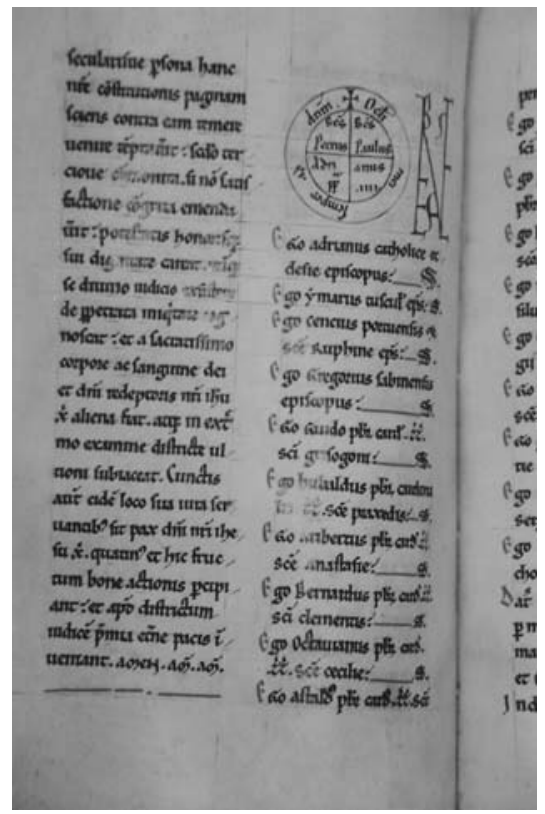

ANUARIO de Estudios MedieVales (AEM) — 36/1, 2006 ISSN 0066-5061. 


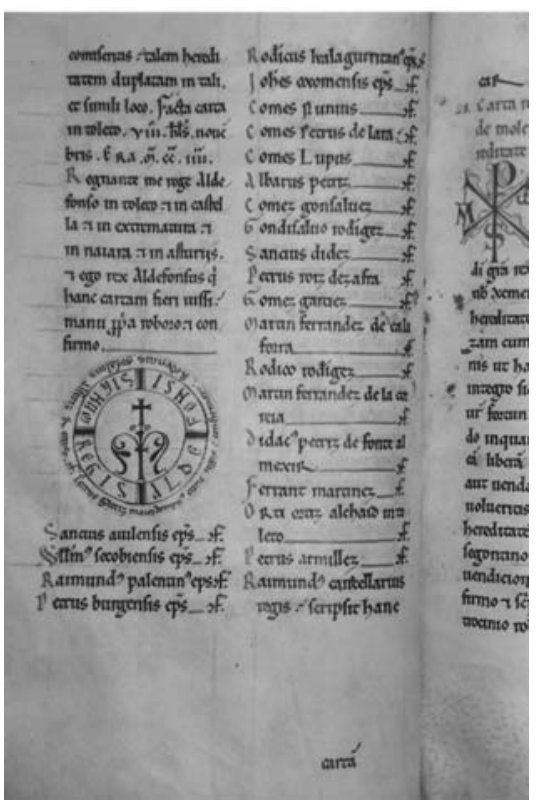

Lámina 7. Fol. 38 v.

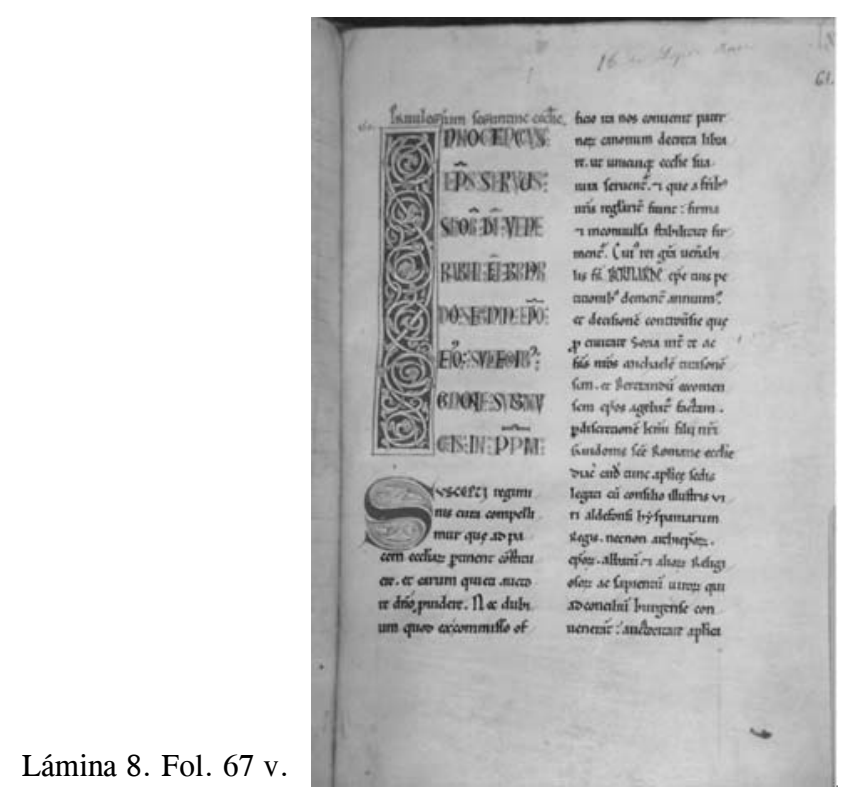

ANUARIo de Estudios Medievales (AEM) — 36/1, 2006 ISSN 0066-5061. 


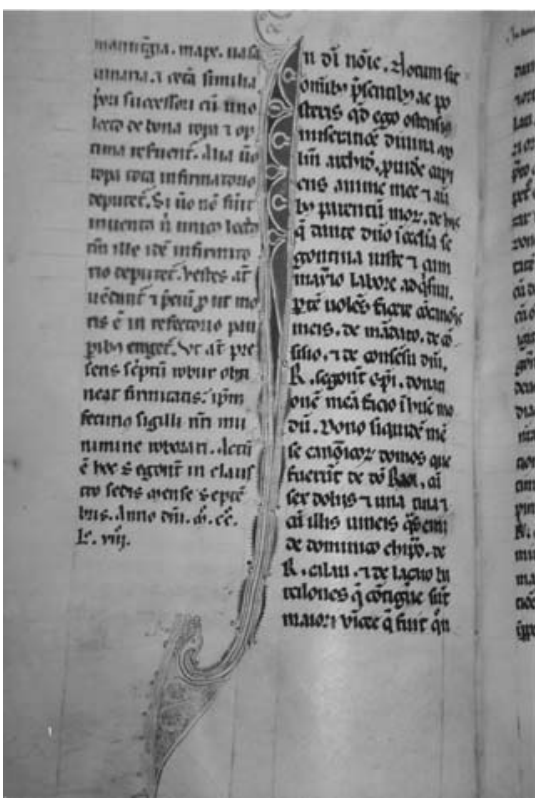

Lámina 9. Fol. 115 v.

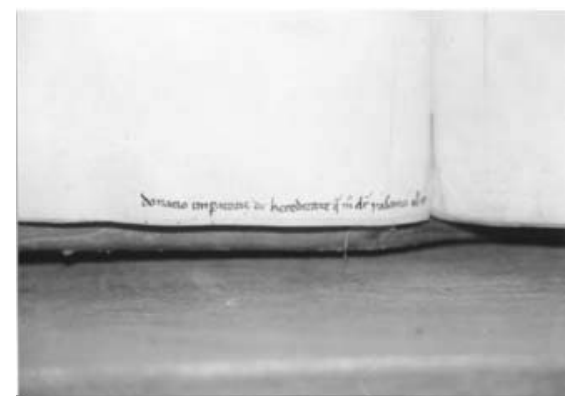




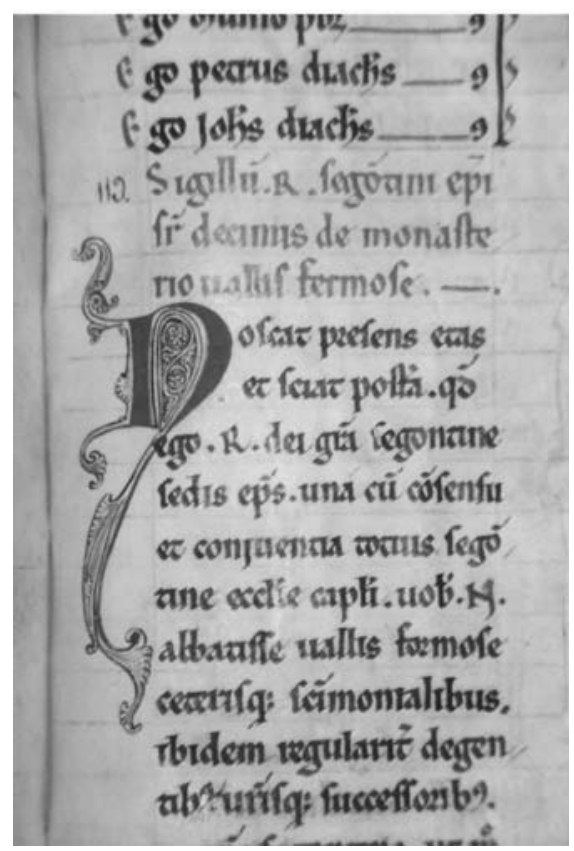

Lámina 11.

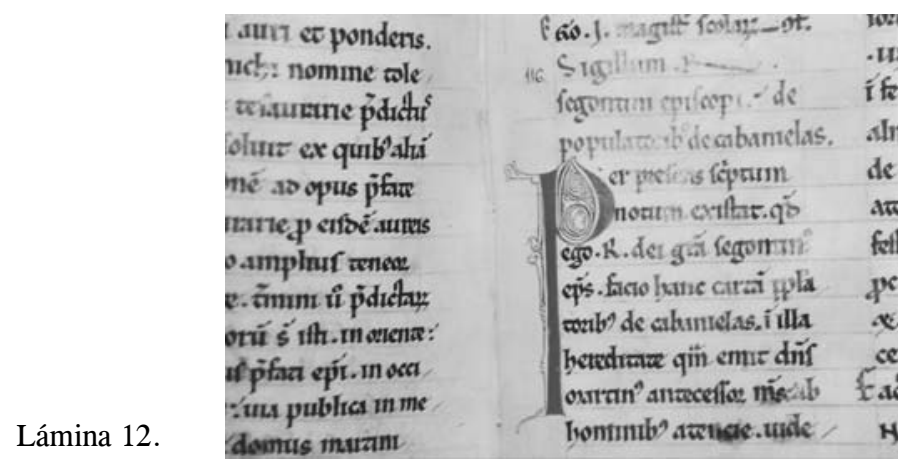

